\title{
Application of antigen presenting cell-targeted nanovaccine delivery system in rhabdovirus disease prophylactics using fish as a model organism
}

\author{
Chen Zhang ${ }^{1}$, Gao-Xue Wang ${ }^{1}$ and Bin Zhu ${ }^{1,2^{*}}$ (1)
}

\begin{abstract}
Background: Targeted delivery of virus-associated antigens to professional antigen-presenting cells (APCs) is considered as an efficient strategy to enhance the pyrophytic effect of vaccines against rhabdovirus disease.

Materials and methods: In this study, we constructed a targeted carbon nanotubes-based vaccine deliver system (SWCNTs-MG) which can recognize the signature receptor (mannose) of APCs. An environmentally and economically important disease called spring viremia of carp (SVC) was studied as a model to evaluate the feasibility of singlewalled carbon nanotubes (SWCNTs) conjugated with mannosylated antigen for rhabdovirus prevention.

Results: Results showed that SWCNTs-MG could cross into fish body and present to internal immune-related tissues through gill, muscle and intestine within $6 \mathrm{~h}$ immersed vaccination. With further modification of mannose moiety, the obtained nanovaccine showed enhanced uptake by carp macrophages and immune-related tissues, which would then trigger strong immune responses against spring viremia of carp virus (SVCV) infection. Moreover, the survival rate of fish vaccinated with SWCNTs-MG (30 mg/L) was 63.5\% after SVCV infection, whereas it was $0 \%$ for the control group.

Conclusion: This study not only provide a theoretical basis and research template for the application of targeted nanovaccine system in aquatic animals, but also play an important role in supporting development of healthy aquaculture and ensuring the safety of aquatic products and ecology.
\end{abstract}

Keywords: Targeted nanovaccine, Mannose, Carbon nanotubes, Rhabdovirus, Immune response

\section{Introduction}

Rhabdoviridae-related viruses are a kind of viruses with negative sense single strained RNA and a variety of hosts $[1,2]$. Diseases caused by rhabdovirus pose a serious threat to most of the vertebrates [3-5]. Prophylactic vaccine is considered as the most effective measure to prevent rhabdovirus infection [6,7]. However, due to the

*Correspondence: zhubin1227@126.com

${ }^{2}$ Northwest A\&F University, Xinong Road 22nd, Yangling, Shaanxi 712100, China

Full list of author information is available at the end of the article biological barrier (such as skin, selective permeability of the cell membrane, gastrointestinal tract and so on), it is not easy for most biological macromolecules including antigen proteins and plasmid enter into host and play a role, which led to the less robust immune responses of current rhabdovirus vaccines [8-10]. Therefore, developments in efficient delivery technologies for vaccine play a vital role to prevent rhabdovirus diseases.

An effective nanovaccine delivery system is commonly composed of the antigens, delivery carrier, and adjuvant $[11,12]$. For most rhabdovirus, the surface glycoprotein

c) The Author(s) 2020. This article is licensed under a Creative Commons Attribution 4.0 International License, which permits use, sharing, adaptation, distribution and reproduction in any medium or format, as long as you give appropriate credit to the original author(s) and the source, provide a link to the Creative Commons licence, and indicate if changes were made. The images or other third party material in this article are included in the article's Creative Commons licence, unless indicated otherwise in a credit line to the material. If material is not included in the article's Creative Commons licence and your intended use is not permitted by statutory regulation or exceeds the permitted use, you will need to obtain permission directly from the copyright holder. To view a copy of this licence, visit http://creativecommons.org/licenses/by/4.0/. The Creative Commons Public Domain Dedication waiver (http://creativecommons.org/publicdomain/zero/1.0/) applies to the data made available in this article, unless otherwise stated in a credit line to the data. 
(G) of rhabdovirus is considered as a major antigen that could induce a primary host immune response. As the typical rhabdovirus, SVCV G protein is the most commonly protein used in SVCV vaccine constructs [13]. As a promising carrier, single-walled carbon nanotubes (SWCNTs) has been widely used for antigens and drugs delivery attributable to its excellent properties, such as biocompatibility, needle-like structure, and high carrying capacity [14-16]. Specifically, SWCNTs are uniquely equipped to deliver cargos (such as antigens and drugs) across biological membranes [17], their use for vaccination could allow effective utilization of antigens that have previously not been able to induce adequate or appropriate responses, as well as providing significant means of enhancing and modulating immune response [18]. In order to further enhance the efficacy of vaccination, the adjuvants are essential components and usually co-administrated with immunogens, especially for the weak immunogens [19]. As the efficient adjuvant and the targeted ligands which can specifically recognize the signature receptor (mannose) on antigen-presenting cells (APCs) such as macrophages and dendritic cells, mannose has been widely used for the construction of targeted nanovaccine [20,21]. Therefore, mannose was modified and conjugated to antigens by chemical synthesis in this study.

To date, targeted delivery has been widely used in cancer treatment, with few studies focusing on the prevention of viral disease especially the rhabdovirus. In this study, spring viremia of carp virus (SVCV) was studied as a model to evaluate the feasibility of targeted nanovaccine in preventing rhabdovirus diseases. SVCV is a cytopathic virus belonging to the genus Vesiculorius of the family Rhabdoviridae [22]. The notable advantages of employing SVCV as the model including the followings: (1) Safety, aquatic animals constitute the narrow nature host range of SVCV, and humans are nonsusceptible. (2) Representative to rhabdovirus, SVCV is a typical rhabdovirus with its genome composed of a negative, singlestranded RNA. (3) Widespread distribution and easy accessibility, SVCV has been reported in worldwide and is susceptibility to almost cyprinid [22-25].

In this study, a targeted delivery system based on SWCNTs conjugated to mannosylated antigens was constructed. The targeting ability and uptake kinetics of the targeted delivery system was checked both in vivo and in vitro. Moreover, for demonstrating the targeted delivery system could act as an effective platform for prophylactic vaccines against rhabdovirus disease, the immune responses in vaccinated fish were evaluated. This work highlights the great potential of SWCNTs-based targeted vaccine delivery system as an attractive platform to prevent rhabdoviral diseases.

\section{Results and discussion}

\section{Construction and characterization of targeted delivery system}

Antigen, adjuvant, and delivery carrier are the key elements for effective nanovaccine delivery system. As illustrated in Fig. 1a, SVCV antigen protein $(G)$ were modified with mannose, and then encapsulated with SWCNTs to construct the targeted nanovaccine delivery system (SWCNTs-MG). Furthermore, the obtained SWCNTsMG nanovaccine was characterized. As revealed by scanning electron microscopy (SEM) and transmission electron microscopy (TEM), the constructed nanovaccine is a tubular structure with its surface conjugated with mannosylated antigen proteins (Fig. 1b, c). Further confirmation of the synthetic constructs was performed using X-ray photoelectron spectroscopy (XPS) spectrum. The XPS spectrum of SWCNTs-MG shows two characteristic peaks of SWCNTs (carbon $(288 \mathrm{eV})$ and oxygen $(532 \mathrm{eV})$ ) (Fig. 1d). The particle size and zeta potential of the vaccines were analyzed. As show in Fig. 1e, the average sizes of o-SWCNTs, SWCNTsG, and SWCNTs-MG were $133.46 \mathrm{~nm}, 196.58 \mathrm{~nm}$, and $238.43 \mathrm{~nm}$, respectively. Upon conjugated with mannosylated antigens, the resulting SWCNTs showed increased size to be about $105 \mathrm{~nm}$. Moreover, zeta potential revealed a negative surface charge $(-19.83 \pm 1.49 \mathrm{mV})$ for SWCNTs which decrease to $-24.86 \pm 1.57 \mathrm{mV}$ after the conjugation of mannosylated antigens. Moreover, as measured by bicinchoninic acid (BCA) protein assay and phenol-sulfuric acid colorimetry, the SWCNTs-MG nanovacine containing $3.4 \%$ mannose and $40.2 \%$ antigen protein.

\section{Safety evaluation of SWCNTs-MG}

Vaccine safety is first priority to be considered before vaccination. After the SWCNTs-MG nanovaccine was constructed, its safety was evaluated in vitro and in vivo. The potential cytotoxicity of SWCNTs-MG toward macrophages and EPC cells was determined by the cell viability assy. As Fig. 2a shown, after macrophages and EPC cells incubated with $40 \mu \mathrm{g} / \mathrm{mL}$ SWCNTs-MG for $24 \mathrm{~h}$, the survival rate of both kinds of cells shown no significant difference with control groups. The safety evaluation was also performed in common carp, after common carp immersed with $60 \mathrm{mg} / \mathrm{L}$ SWCNTs-MG for $24 \mathrm{~h}$. As depicted in Fig. 2b, no damage nor abnormality was found in vaccinated fish brain, gill, intestine, kidney, liver, and spleen. Besides, within $60 \mathrm{~d}$ after immersion immunization, there was no lesion nor abnormality in vaccinated carp when compared with control group. This study indicate SWCNTs-MG nanovaccine has good biocompatibility in vitro and in vivo.

Up to now, the safety of carbon nanotubes remains controversial. Some studies suggested that carbon nanotubes may be toxic: Warheit indicated that pulmonary exposures to SWCNT in rats produced a non-dose-dependent series 
a

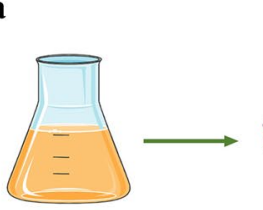

b

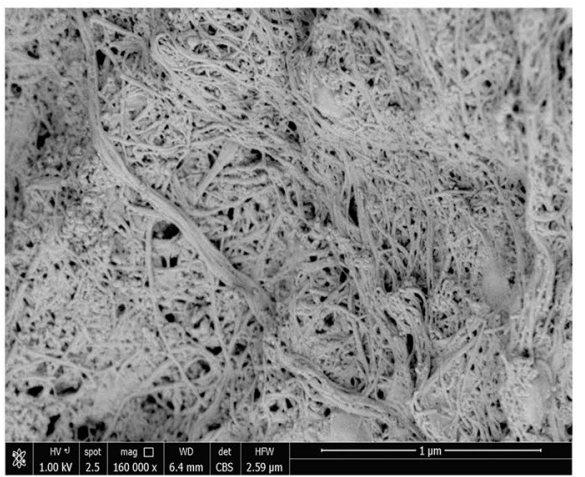

d

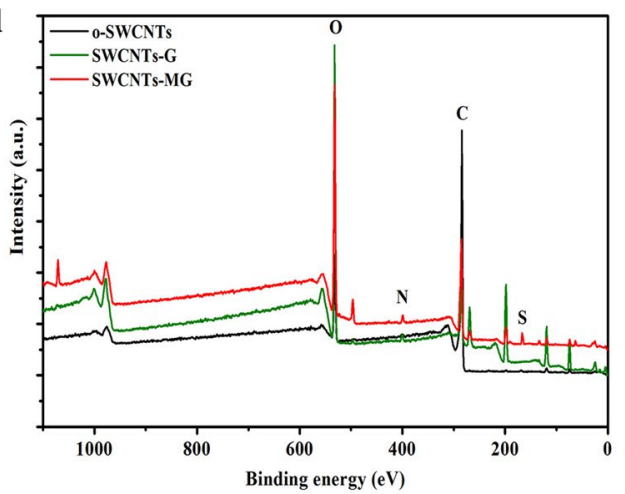

Mannose

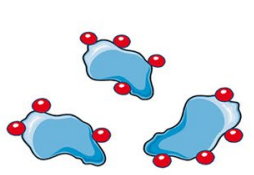

MG

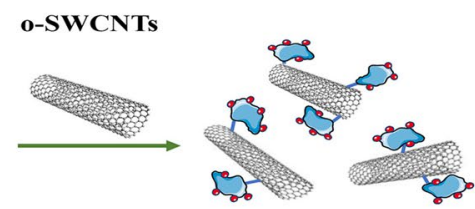

SWCNTs-MG

c

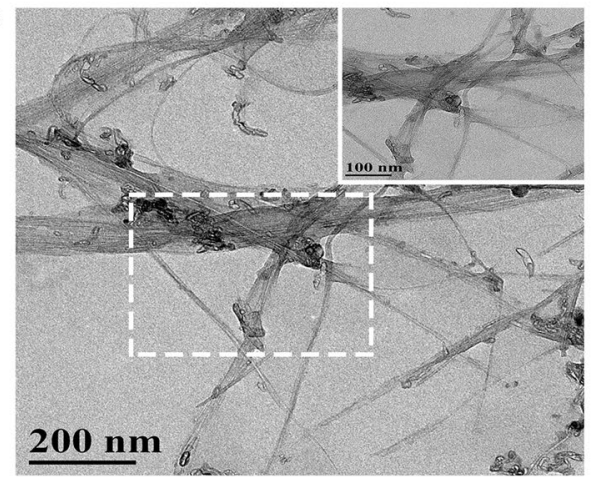

e

\begin{tabular}{|c|c|c|}
\hline Samples & Size $(\mathrm{nm})$ & Zeta potential $(\mathrm{mV})$ \\
\hline 0-SWCNTs & $133.46 \pm 6.58$ & $-19.83 \pm 1.49$ \\
\hline SWCNT-G & $196.58 \pm 2.37$ & $-37.54 \pm 4.18$ \\
\hline SWCNTs-MG & $238.43 \pm 5.73$ & $-24.86 \pm 1.57$ \\
\hline
\end{tabular}

Fig. 1 Characterization of nanovaccine. a Schematic illustration to show the step-by-step preparation of SWCNTs-MG nanovaccine. $\mathbf{b}$ Representative scanning electron microscopy image and c transmission electron microscopy image of SWCNTs-MG nanovaccine. $\mathbf{d}$ X-ray photoelectron spectroscopy analysis. e Particle size and zeta potential analysis

of multifocal granulomas, which were evidence of a foreign tissue body reaction and were nonuniform in distribution and not progressive beyond 1-month postexposure [26]. Zhu conjectured that high concentration CNTs (above $100 \mathrm{mg} / \mathrm{L}$ ) might induce toxicity in rare minnow (Gobiocypris rarus), in addition, o-SWCNTs (188.2 mg/L) could induce apoptosis in S. cerevisiae cells, and oxidative stress in activation of the mitochondria-dependent apoptotic pathway $[27,28]$. However, no conclusive evidence could verify the toxicity of CNTs. Numerous studies indicated CNTs is biocompatibility: Rats were used as the model to analyze the toxic of SWCNTs, results showed that rat exposure to SWCNTs did not produce mortality, changes in clinical signs, or body weights during the observation period [29]. Dumortier indicated that functionalized carbon nanotubes are non-cytotoxic and preserve the functionality of primary immune cells [30]. In this study, we have purified and functionalized the SWCNTs, and then conjugated the SWCNTs with mannosylated antigen proteins. Studies suggested that when carbon nanotubes are purified and functionalized, their biological toxicity could be reduced [31-33]. Notably, after functionalized carbon nanotubes were further chemically modified with active substances (such as antigenic proteins), their biocompatibility is further enhanced and water-dispersibility is improved [34].

\section{Celluar uptake of nanovaccine by cyprinid macrophage}

It is important for immune responses induced by vaccines that viral antigens are processed and presented by APCs [35]. Therefore, the cellular uptake of nanovaccine by APCs would be important for the efficacy of nanovaccines. To evaluate the cell uptake of nanovaccines by 

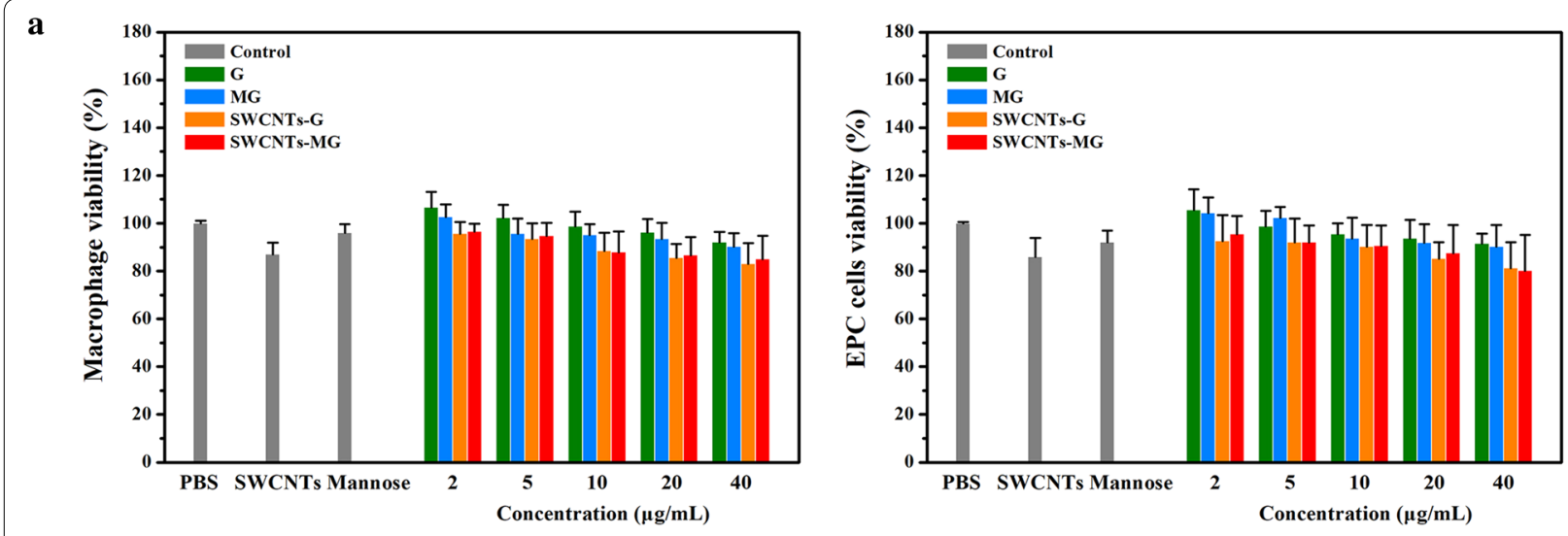

b Brain

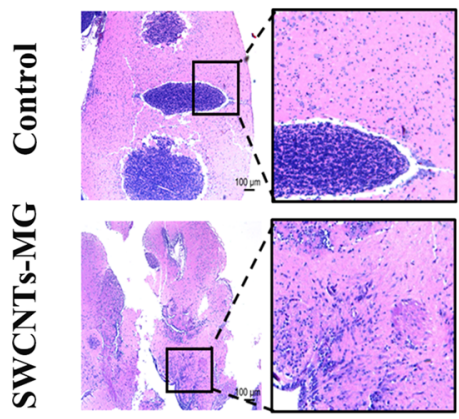

Intestine

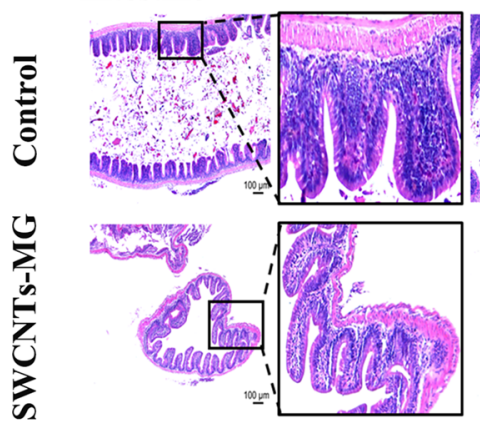

Liver

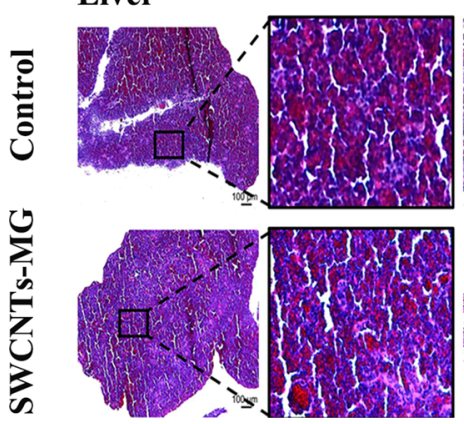

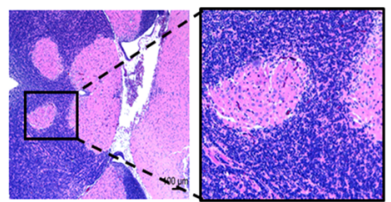
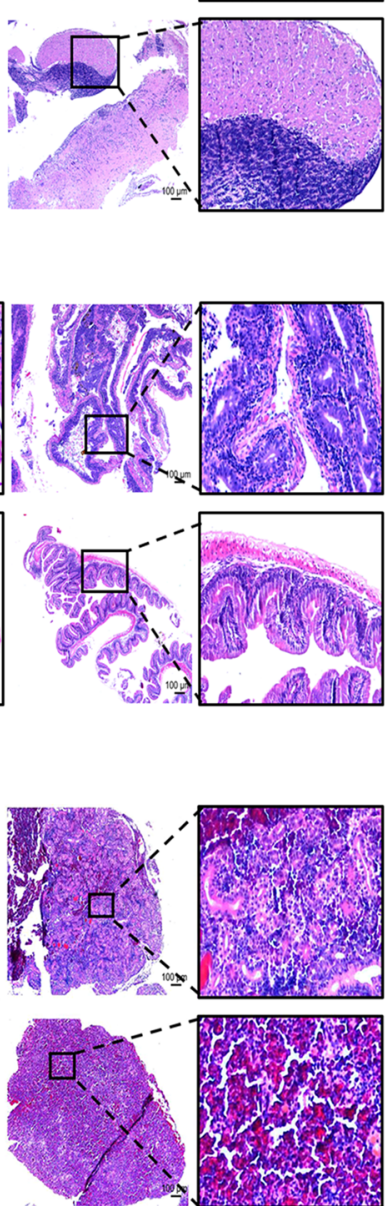

Gill

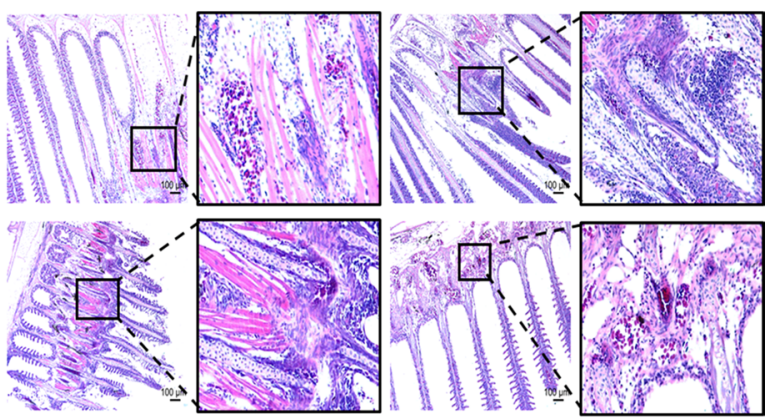

\section{Kidney}
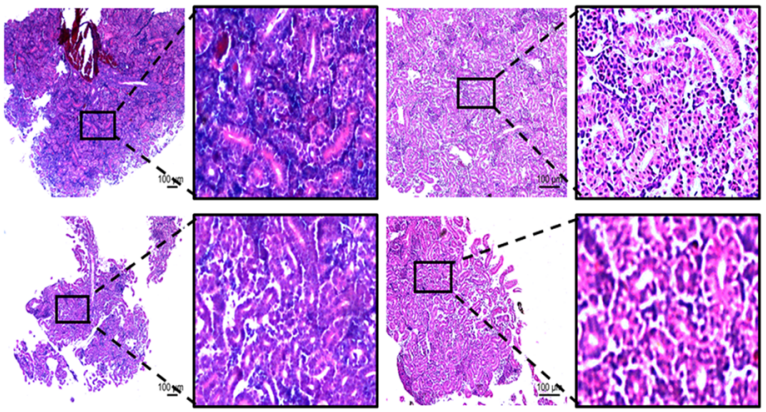

Spleen
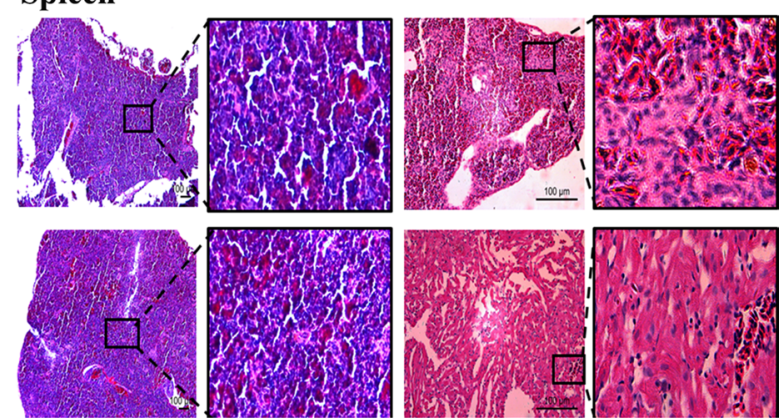

Fig. 2 Safety evaluation of nanovaccine in vivo and in vitro. a Relative cell viability of carp macrophage and EPC cells after incubation with different concentrations of G, MG, SWCNTs-G and SWCNTs-MG for 24 h. $\mathbf{b}$ Histopathologic analyses of H\&E-stained tissue sections from the brains, gills, intestines, kidneys, livers, and spleens of SWCNTs-MG vaccinated fish after immersed for $10 \mathrm{~h}$, scale bar: $100 \mu \mathrm{m}$ 
APCs, macrophages were incubated with different vaccines (G, MG, SWCNTs-G, and SWCNTs-MG) labeled with FITC for the flow cytometric analysis and immunofluorescence, respectively. As shown in Fig. 3a, b, SWCNTs-MG showed significantly enhanced cellular uptake by macrophages compared to SWCNTs-G (without mannose modification) $(P<0.01)$. Such a phenomenon was also confirmed by confocal fluorescence imaging of macrophages incubated with these nanovaccines (Fig. 3c). The enhanced cell uptake of nanovaccines containing antigen and adjuvant by APCs would be greatly favorable for inducing stronger immune responses and more effective vaccination.

\section{Detection of nanovaccine in fish tissues}

Due to skin barrier and selective permeability of the cell membrane, it is not easy for most biological macromolecules including proteins, drugs, and plasmid enter into fish body, which is also the obstacle for vaccine applications [36]. Moreover, the amount of vaccines enter into immune tissues would greatly determine the quality of induced immunities [37]. To tackle the obstacle of vaccines entering
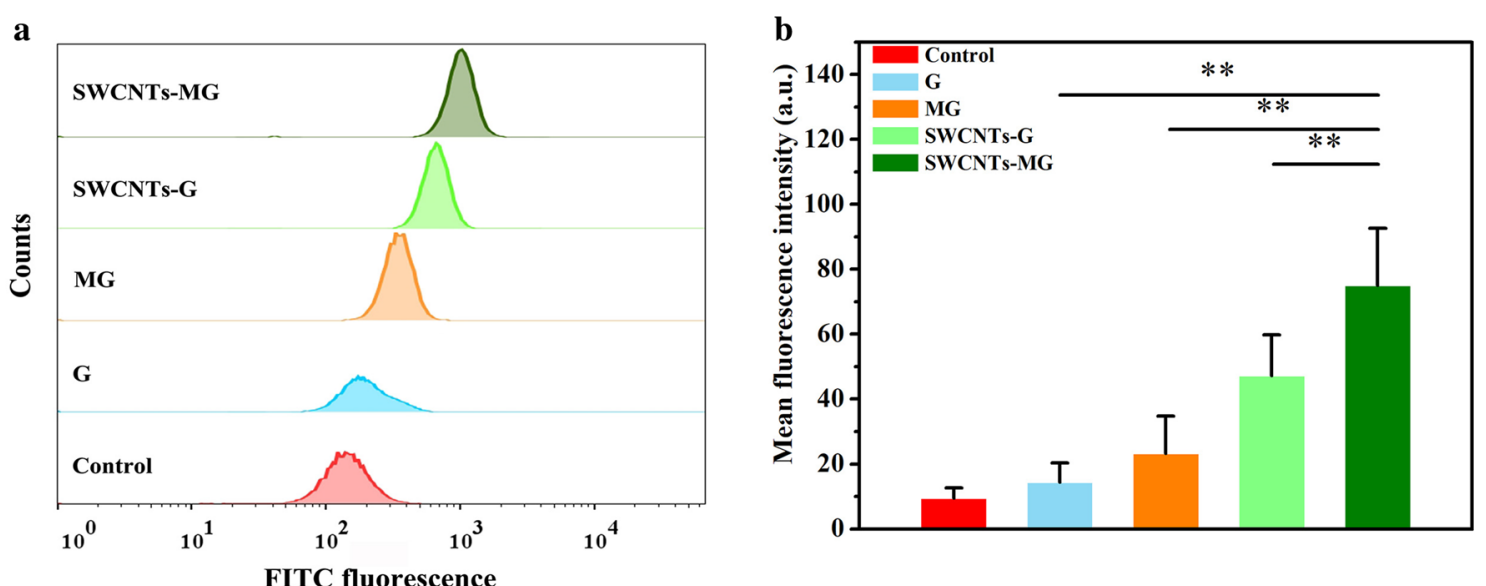

c Cy3

DAPI
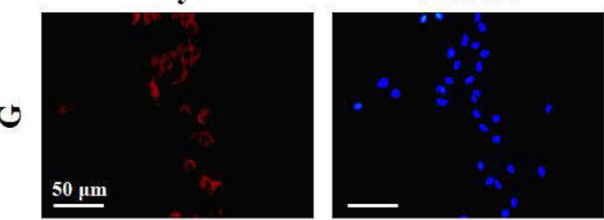

FITC

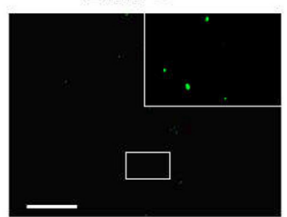

Merge

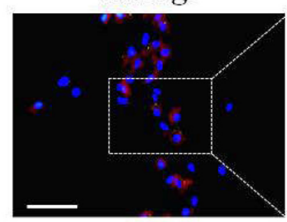

Magnify
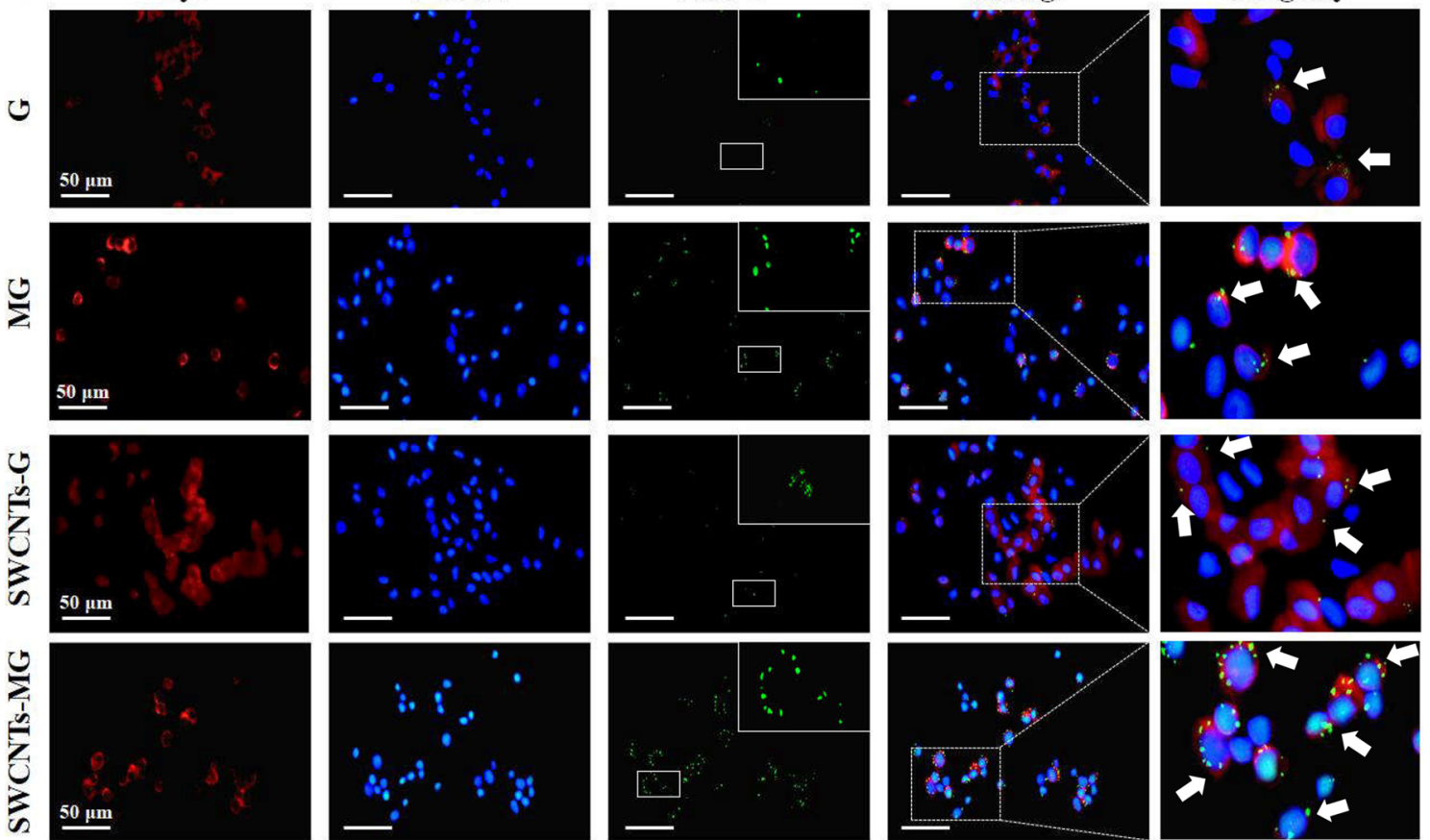

Fig. 3 Cellular uptake of nanovaccine by carp macrophage in vitro. a Uptake of FITC labelled nannovaccines by carp macrophage in vitro. $\mathbf{b}$ Mean florescence intensity of cell uptake capability. c Representative confocal microscopic images of carp macrophage incubated with G, MG, SWCNTs-G, and SWCNTs-MG respectively. Vaccines were labeled with FITC (green channel, white arrows), respectively; The cell nucleus was labeled with DAPI (blue channel); The mannose receptor was labeled with Cy3 (red channel) 
into host, herein SWCNTs was used as the vaccine carrier. As a promising vaccine carrier, SWCNTs possess numerous properties including penetrability, high carrying capacity, biocompatibility and so on [38]. As shown in Fig. 4, the content of SWCNTs-MG nanovaccines in vaccinated fish muscle, intestine, kidney, spleen, and liver were significantly higher than other vaccines (G, MG, and SWCNTsG) respectively $(P<0.01)$ with stronger green fluoresces. These results suggest that the constructed nannovaccine delivery system, using SWCNTs as carrier and mannose as targeting ligand/adjuvant, could efficiently delivery nanovaccine into the immune related tissues via bath administration. With more antigens enter into immune related tissues, higher immune response would be induced.

\section{The maturation of APCs induced by nanovaccines}

After the immature APCs captured antigens, it could be stimulated into a matured status, which could lead to antigen presentation and then activate $\mathrm{T}$ cells with the subsequent immune response induced. As the surface markers for mature APCs, the expression level of MHC-I, MHC-II, and CD80/86 could reflect the maturation of APCs. Therefore, to evaluate the abilities of these nanovaccines to stimulate APCs maturation and antigen presentation, the expression of MHC-I, MHC-II, and CD80/86 in vaccinated fish were analyzed by ELISA. As depicted in Fig. 5, compared to samples treated with PBS and SWCNTs, those vaccinated with mannose, G, MG, SWCNTs-G, and SWCNTsMG showed significantly increased secretion levels of MHC-I, MHC-II, and CD80/86, respectively. In addition, the highest secretion levels of these molecules were found in samples treated with SWCNTs-MG. Therefore, these data indicate that SWCNTs-MG nanovaccine appears to be the effective method for in vivo activation of APCs.

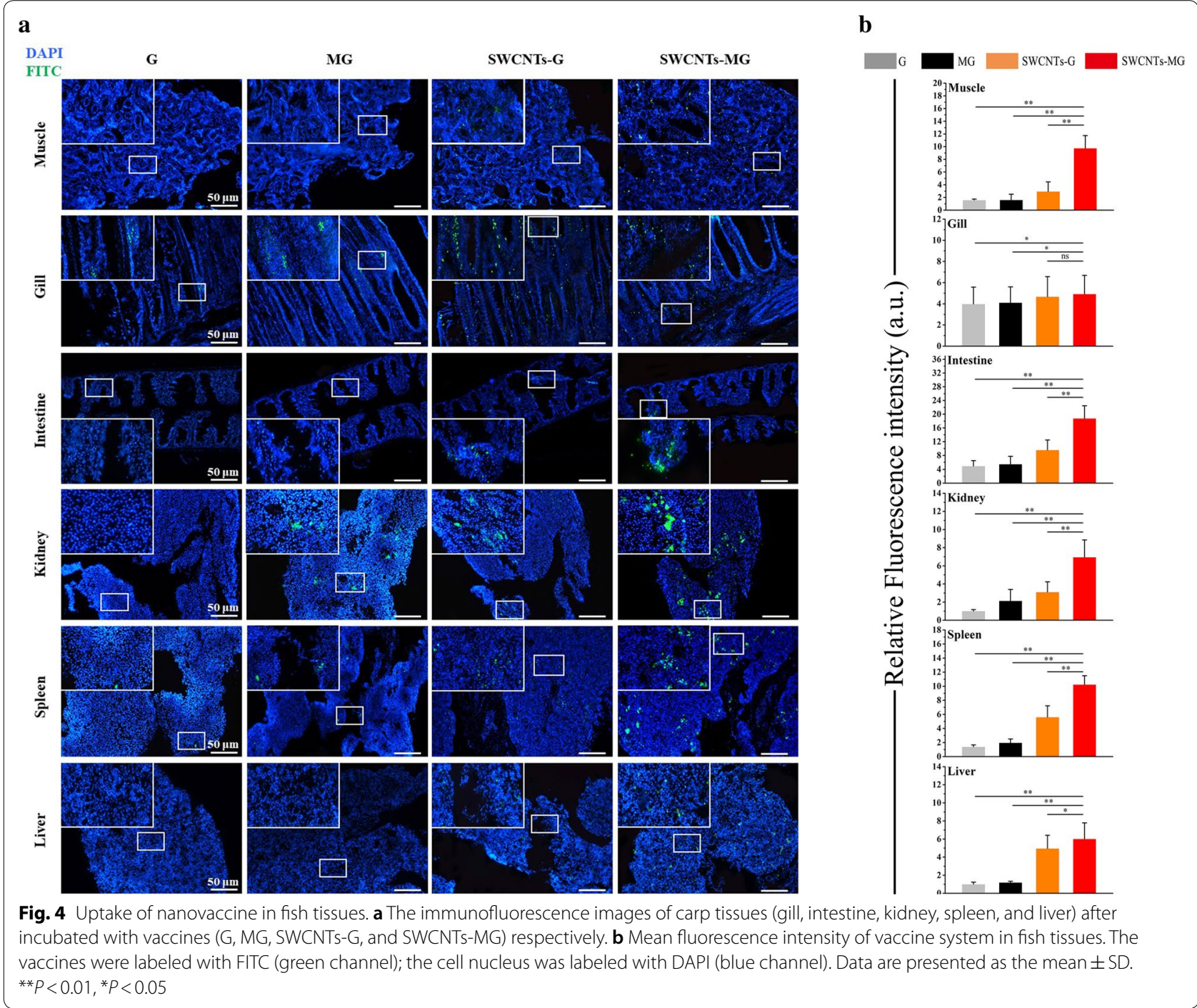




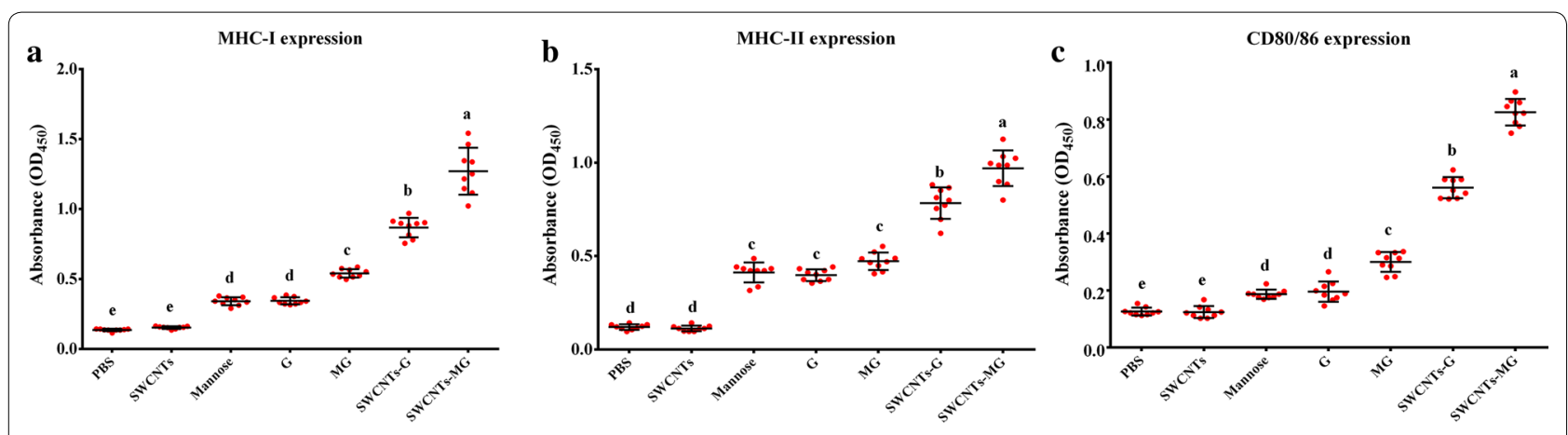

Fig. 5 Effect of nanovaccines on antigen presenting cells maturation and antigen presentation. Data are represented as mean $\pm S D(n=9)$. Data at the same sampling time with different letters are significantly different $(P<0.05)$

$\mathbf{a}$

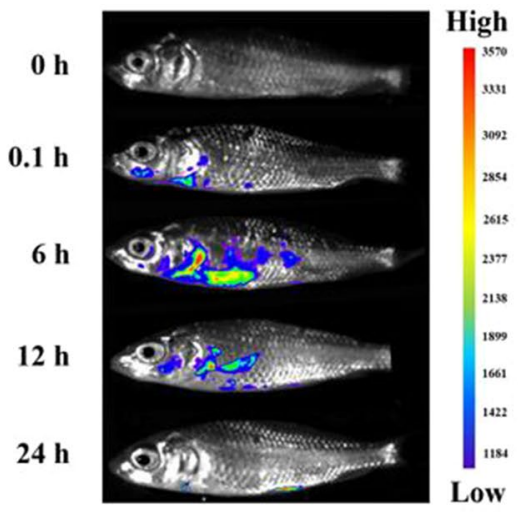

c $\mathbf{0 ~ h}$

$0.1 \mathrm{~h}$

$6 \mathrm{~h}$
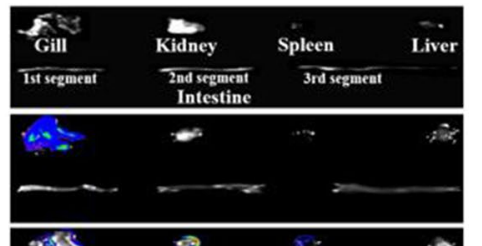

$12 \mathrm{~h}$

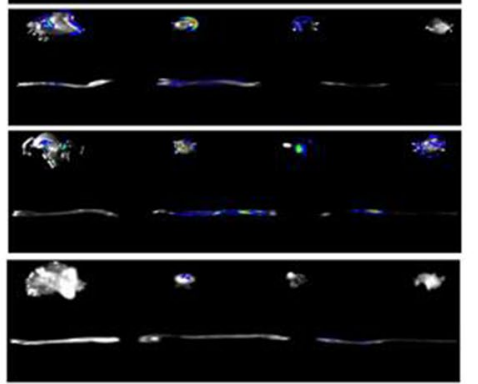

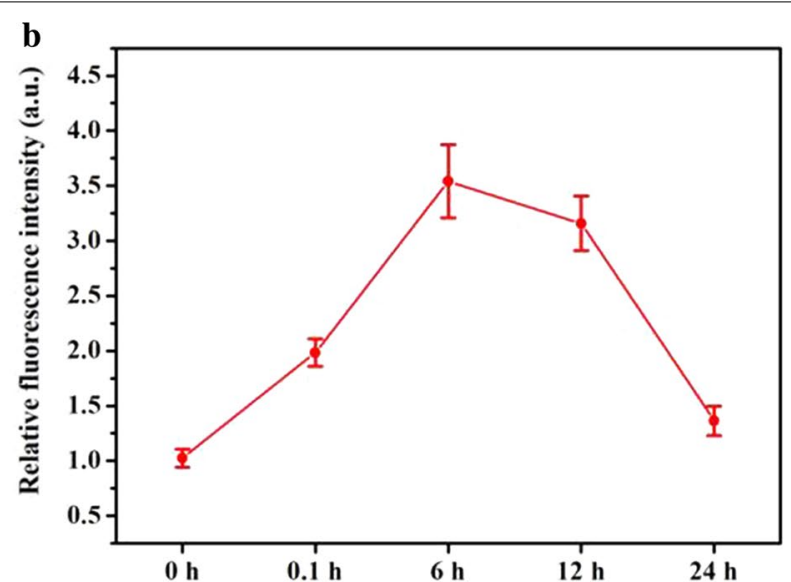

d

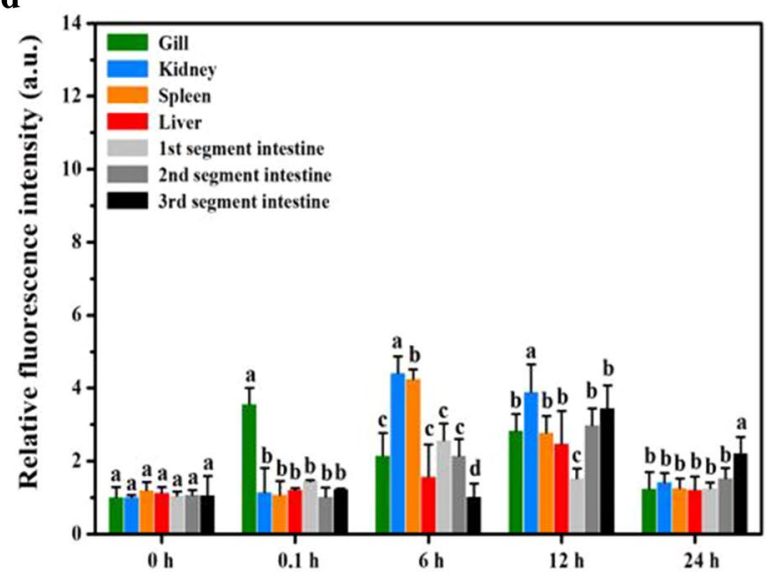

Fig. 6 In vivo and ex vivo fluorescence images of vaccine system in vaccinated fish. a Representative in vivo fluorescence images of common carp at different time points after vaccination; $\mathbf{b}$ Quantitative fluorescence signals of vaccinated fish; $\mathbf{c}$ representative ex vivo fluorescence images of isolated fish tissues at different time points; $\mathbf{d}$ Quantitative fluorescence signals of different fish tissues. Data are means for three assays and represented as mean $\pm S D$. Data at the same sampling time with different letters are significantly different $(P<0.05)$

\section{The delivery kinetics of targeted nanovaccine}

To investigate the delivery kinetics of targeted nanovaccine in vaccinated fish, common carp $(1.0 \pm 0.2 \mathrm{~g})$ were exposed to SWCNTs-MG nanovaccine by immersion for $6 \mathrm{~h}$ and then transferred to standard dilution water. Fluorescence imaging was used to track SWCNTs-MG nanovaccine labeled with FITC. As shown in Fig. 6, from the beginning of immersed immunity at $0 \mathrm{~h}$ to the end 
of vaccination at $6 \mathrm{~h}$, the content of SWCNTs-MG was gradually increased. Notably, the content of SWCNTs in kidney and spleen of vaccinated fish were significantly higher than that in other tissues $(P<0.05)$. Numerous studies indicated that kidney and spleen contain large amounts of macrophages [39]. The higher content of nanovaccine in these two immune organs reflecte the targeted delivery capacity of SWCNTs-MG nanovaccine, which showed that SWCNTs-MG could cross into fish body and present to internal immune-related tissues through gill, muscle and intestine within $6 \mathrm{~h}$ immersed vaccination. After the vaccinated fish transferred to standard dilution water, the intensity fluoresce of SWCNTs-MG nanovaccine was gradually decreased. Up to $24 \mathrm{~h}$, the fluoresce was barely visible, which suggeste SWCNTs could excrete from the fish body. Zhu indicated that the CNTs could completely excreted out from the larvae at around 144 h [27], which is corresponding with our results. However, the more specific delivery kinetics of targeted nanovaccine needs further investigation. The current delivery kinetics of targeted nanovaccine suggests the targeted delivery ability and biocapacity of SWCNTs-MG nanovaccine.

\section{The immune response in vaccinated fish}

To evaluate the prophylactic effects of targeted nanovaccine, we analyzed the immune response in vaccinated fish. As depicted in Fig. 7, SWCNTs-MG could induce higher levels of immune response including serum antibody production, enzyme activities, and immune genes expression than other vaccines (G, MG, and SWCNTs).

Results of the specific serum antibody and non-specific parameters reveal that eliciting powerful and long-lasting humoral or cellular immune response could be induced in vaccinated fish (Fig. 7b, d). Although production of antibodies does not necessarily correlate with protection and could vary with vaccine formulation, fish size, and environment [40], but to a certain extent, the antibody level could reveal the immune effect of vaccine [41, 42]. The enhancement of specific serum antibody response in vaccinated fish was prominent, in addition, the antibody level in SWCNTs-MG vaccinated fish were significantly higher than that in other vaccinated fish (G, MG, and SWCNTs-G) at the same dose. The significant enhancement of enzyme activities such as complement activities, superoxide dismutase (SOD), acid phosphatase (ACP), and alkaline phosphatase (AKP) activities were observed in SWCNTs-MG vaccinated fish. The complement system represents a major component innate immunity and also acts to enhance the adaptive immune response [43]. The improved complement activity in SWCNTs-MG vaccinated fish reveal the enhanced activation of complements pathway. As a vital antioxidant enzyme, SOD is an important factor for initiating the host immune response by regulating innate and acquired immunity [44]. ACP and AKP assays are the symbols of macrophage

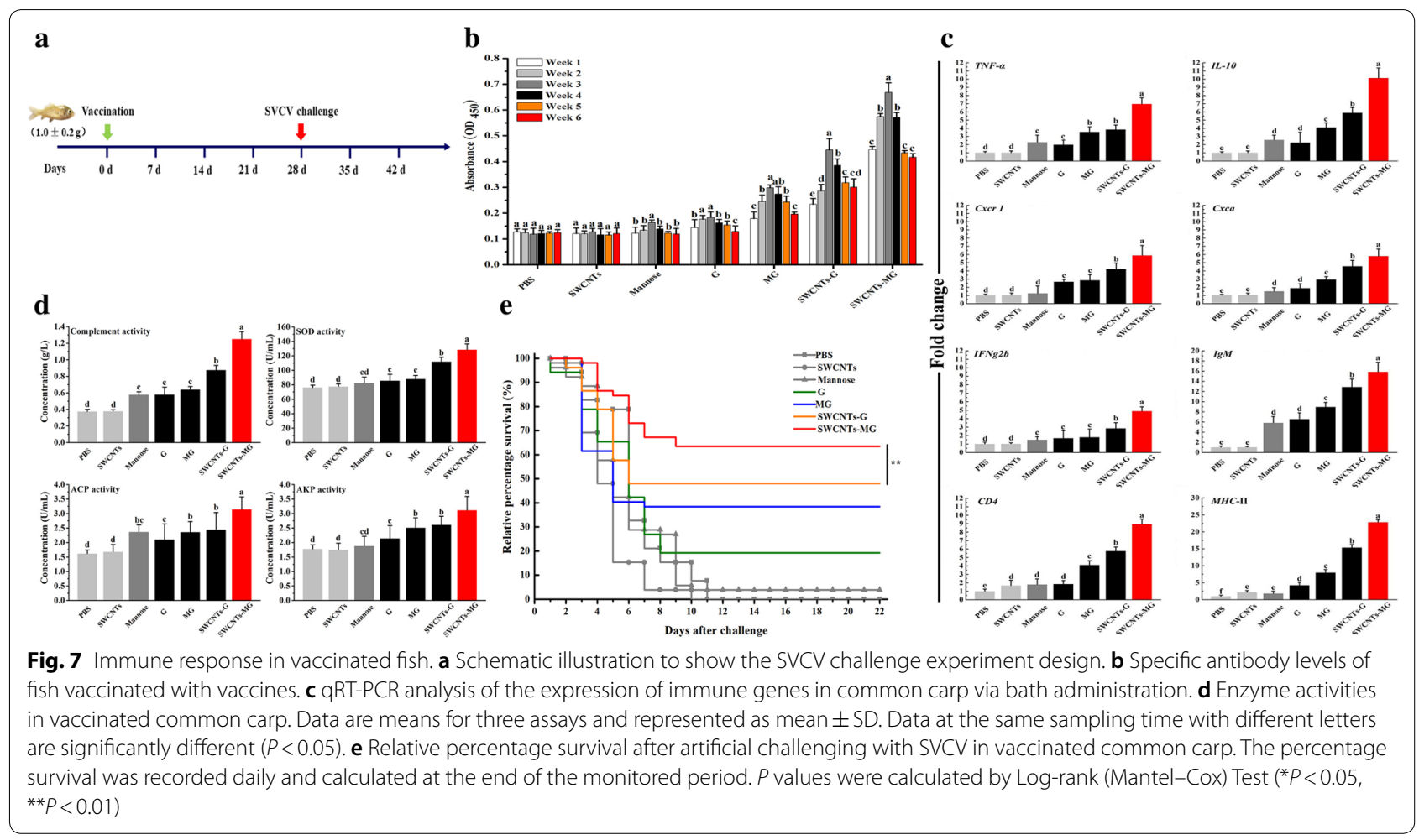


activation that reflect the ability of intracellular digestion of phagocytized antigens in the immune system [45].

To further investigate the defense mechanisms induced by the constructed SWCNTs-MG nanovaccine against SVCV infection, the expressions of immune-related genes were analyzed following vaccination. As shown in Fig. 7c, the immune-related genes including immunoglobulin $(I g M)$, tumour necrosis factor alpha one (TNF$\alpha)$, interleukin $10(I L-10)$, CXC chemokine receptor-1 (Cxcr 1), CXC chemokine a (Cxca), interferon gamma2beta $(I F N g 2 b)$, cluster of differentiation $4(C D 4)$, and major histocompatibility complex class II (MHC-II) were significantly up-regulated in all vaccinated carps $(P<0.05)$. Importantly, the expressions of these immunerelated genes in SWCNTs-MG vaccinated fish were significantly higher than other vaccines (G, MG, and SWCNTs-G) $(P<0.05)$. Interestingly, consistent with the increased production of specific serum antibodies, the expression of $I g M$ gene was significantly up regulated in SWCNTs-MG vaccinated fish. IgM is a major component of the humoral immune system of teleost fish [46, 47]. The significantly enhancement of IgM in SWCNTs-MG treated fish indicate the enhanced immune response could be induced by SWCNTs-MG nanovaccine. Cytokines play a vital role in regulating host defense network [48, 49]. TNF- $\alpha, I L-10, I F N g 2 b, C x c r 1$, and $C x c a$ are the important component of innate immunity [5052]. The activation of innate immunity mediated by these cytokines could then condition the initiation of specific adaptive immune responses [53]. The expression of CD4 and $M H C$-II are the typical markers reflecting the exogenous antigen presentation, the higher expression levels of CD4 and MHC-II lead to increased advantages in terms of antigen presentation [54].

Specifically, SVCV challenge was used to further investigate the prophylactic effects of SWCNTs-MG nanovaccine. As depicted in Fig. 7e, the highest survival rate (63.5\%) was observed in SWCNTs-MG vaccinated fish. Furthermore, as an adjuvant and targeted ligand, mannose can enhance $15.4 \%$ of the survival rate in SWCNTsMG vaccinated fish compared with SWCNTs-G (without mannose) immunized fish.

Taken together, the significantly enhancement of immune response induced by SWCNTs-MG nanovaccine is possibly due to these following reasons: (1) SWCNTs as a promising carrier could pass through cell membranes and delivery more vaccine into the host, namely, SWCNTs make the constructed nanovaccine easier for attachment to specific target tissues and cells; (2) SWCNTs-MG could efficiently target APCs and then activate immune cells to induce strong immune responses; (3) mannose is an adjuvant that can be used to enhance immune response.

\section{Conclusions}

In this study, we have successfully constructed a nanovaccine (SWCNTs-MG) composed of several key elements involving SWCNTs as the vaccine carrier, and mannose as an APCs-recognition moiety. SVCV was studied as a model to evaluate the feasibility of SWCNTs conjugated with mannosylated antigens against rhabdovirus infection. SWCNTs-MG could cross into fish body and present to internal immune-related tissues through gill, muscle and intestine within $6 \mathrm{~h}$ immersed vaccination. Moreover, mannose modification could facilitate the binding and cellular uptake of nanovaccine by APCs and further enhance host-protective immune responses against SVCV infection. Therefore, the study so far indicated that SWCNTs conjugated with mannosylated antigens are effective means against rhabdovirus infection. Importantly, this study shows a bright future for preventing rhabdovirus infection by using SWCNTsbased targeted nanovaccine delivery system.

\section{Materials and methods Virus and cell}

SVCV (strain 0504) kindly provided by Professor Qiang Li (Dalian Ocean University, Dalian, China), was propagated in epithelioma papulosum cyprini (EPC) cells as previously described [55].

Carp macrophage was separated from common carp head kidney by using Fish tissue mononuclear cell separation kit (Solarbio, China). Epithelioma papulosum cyprinid (EPC) cells (kindly provided by Prof. Ling-bing Zeng in Yangtze River Fisheries Research Institute, Wuhan, Hubei, China) were cultured at $25 \pm 0.5^{\circ} \mathrm{C}$ in humidified atmosphere with $5 \% \mathrm{CO}_{2}$, and maintained in Medium 199 (Hyclone, USA) supplemented with 10\% fetal bovine serum (FBS; ZETA LIFE, USA).

\section{Animals}

Common carps (C. carpio) weighing $1.0 \pm 0.2 \mathrm{~g}$ were purchased from a local SVCV-free farm in Yangling (shannxi, China). Carps were bred in laboratory for 28 days prior to vaccination. The water temperature for common carps were maintained at $20-23{ }^{\circ} \mathrm{C}$. Commercial dry feed pellets (Hellow Fish Dry Pellets; CVM Products, Beijing, China) were used to fed carps twice daily. All of the experimental animals were handled according to the guidelines of the Animal Experiment Committee, Northwest A\&F University.

\section{Functionalized SWCNTs}

Pristine SWCNTs purchased from Chendu Organic Chemicals Co., Ltd., Chinese Academy of Sciences (Chendu, China) were oxidized by $\mathrm{H}_{2} \mathrm{SO}_{4} / \mathrm{HNO}_{3}$ mixture $(3: 1, \mathrm{v} / \mathrm{v})$ to form carboxyl groups on the surface 
of SWCNTs (o-SWCNTs) under reflux with stirring at room temperature for $48 \mathrm{~h}$ followed by our previous studies [24].

\section{Synthesis of functionalized mannose}

We synthesized 1-(Isothiocyanates phenol)-2,3,4,6-O$\alpha$-D-glucopyranose (Additional file 1: Figure S1F) using well known protection group and coupling chemistry of glycosides. In the first step galactose or glucose were completely protected using acetanhydride in pyridine. Afterward the acetyl protected pyranose was treated with p-nitrophenol in boron trifluoride ethyl ether complex yielding the compound $C$ (Additional file 1: Figure $\mathrm{S} 1 \mathrm{C})$. In the next step the intermediate was reacted with sodium methoxide yielding the compound D (Additional file 1: Figure S1D). Then compound D was hydrogenated by the $\mathrm{Pd} / \mathrm{C}$ to get the compound $\mathrm{E}$ (Additional file 1: Figure S1E). Finally, the target compound F (Additional file 1: Figure S1F) was obtained by the reaction with $\mathrm{CSCl}_{2}$.

General ${ }^{1} \mathrm{H}$ and ${ }^{13} \mathrm{C}$ NMR spectra were measured with a Bruker AM500 spectrometer at 500.23 and $125.78 \mathrm{MHz}$. The chemical shifts are expressed in parts per million ( $\delta$ value) downfield from tetramethylsilane,using tetramethylsilane (TMS) $(\delta=0)$ and/or residual solvents such as Dimethyl sulfoxide $(\delta=2.50)$ as an internal standard. Measurements of mass spectra were performed with an Electro spray-mass spectrometry mass spectrometer (Thermo Scientific ${ }^{\mathrm{TM}}$ LCQ Fleet ${ }^{\mathrm{TM}}$ ). Throughout this study, silica gel H (200-300 mesh; Qingdao Marine Chemical Factory, China) was used for the column chromatography. For TLC plates, Silica gel $\left(\mathrm{GF}_{254}\right)$ (Qingdao Marine Chemical Factory, China) were used for thin layer chromatographic (TLC) analysis, and all of the spots and bands were detected by UV irradiation $(254,365 \mathrm{~nm})$. All chemicals were purchased from Sigma-Aldrich (St. Louis, MO, USA) and used without further purification. Organic solvents were purchased from Sinopharm chemical reagent Co., Ltd and purified by distillation and moisture was excluded from the glass apparatus using $\mathrm{CaCl}_{2}$ drying tubes.

\section{Preparation of SWCNTs-MG}

Purified SVCV G protein was prepared according to our previous study [24]. Modification of SWCNTs-MG was prepared by the chemical combination. Briefly, the functionalized mannose solution $(100 \mathrm{mg} / \mathrm{mL})$ was added into $500 \mathrm{~mL} \mathrm{G}$ protein solution dissolved in boric acid solution and then stirred for $24 \mathrm{~h}$ at room temperature. After the resulting mixture was filtered and washed thoroughly with PBS (pH 7.4), the mannosylated G protein (MG) was obtained. Conjugation of MG with o-SWCNTs to form SWCNTs-MG was according to previous studies.
Conjugation of G/MG/SWCNTs-G/SWCNTs-MG with fluorescein isothiocyanate (FITC) was according to previous study [28].

The SWCNTs-MG was characterized by field emission scanning electron microscopy (FE-SEM, S-4800, Hitachi Ltd., Tokyo, Japan) and high resolution TEM (HR-TEM; Tecnnai G2 F20, USA). An X-ray photoelectron spectroscopy (XPS; PHI-5600, Russia) was used to analyze elemental compositions of o-SWCNTs, SWCNTs-G and SWCNTs-MG. Theromogravimetric analysis (TGA; Mettler Toledo, Switzerland) was carried out to further qualitatively or quatitatively characterize the modification of o-SWCNTs, SWCNTs-G and SWCNTs-MG. Particle size $(\mathrm{nm})$ and zeta potential $(\mathrm{mV})$ of o-SWCNTs, SWCNTs-G and SWCNTs-MG were determined by dynamic light scattering (DLS) analysis (ZEN3600, Malvern, UK).

\section{Safety evaluation of SWCNTs-MG}

For the cytotoxicity of nanovaccine was determined by the 3-(4,5-dimethyl-2-thiazolyl)-2,5-diphenyl-2H-tetrazolium bromide (MTT) assay (Sigma, USA) following the standard protocol.

For the safety evaluation in vivo, 60 carps were bathed in SWCNTs-MG vaccine at $60 \mathrm{mg} / \mathrm{L}$ for $24 \mathrm{~h} .10$ treated carp and 10 normal carp were randomly selected to isolate tissues and organs (brain, gill, intestinal tract, kidney, liver, and spleen), then tissue sections were made and stained. The remaining carp were transferred to clean water for normal feeding. The health and survival of the fish were observed for 60 days.

\section{Cellular and tissular uptake of nanovaccine}

In the cell uptake study, G, MG, SWCNTs-G, and SWCNTs-MG were incubated with $6 \times 10^{7}$ macrophage for $24 \mathrm{~h}$. Macrophages were obtained by centrifugation at $1500 \mathrm{rpm}$ for $2 \mathrm{~min}$. Furthermore, treated macrophages were immunostained with the tissue resident macrophage marker $\mathrm{F} 4 / 80$ primary antibody (1:250, Abcam, Cambridge, England), Cy3-labeled secondary antibody (1:1000, Beyotime. China), and DAPI (Beyotime. China). The cell uptake of fluorescently labeled nanovaccine was analyzed by BD FACSAria flow cytometry (BD, USA) and confocal microscopy (Leica, Germany).

For the detection of nanovaccine in vaccinated fish, carps (80 tail in total) were randomly divided into 4 groups (20 tail/group): G, MG, SWCNTs-G, and SWCNTs-MG group. Each group was immersed with G-FITC, MG-FITC, SWCNTs-G-FITC, and SWCNTs-MG-FITC at $30 \mathrm{mg} / \mathrm{L}$ for $6 \mathrm{~h}$, respectively. After vaccination, fishes were transferred to clean water. Tissues including muscle, gill, intestine, kidney, spleen, and liver were isolated 
from vaccinated fish. Then tissues sections were made and then observed in confocal microscopy (Leica, Germany). Image J software was used to quantify the intensity of fluorescence in each group.

\section{In vivo fluorescence imaging}

Carps $(n=60)$ were randomly selected and treated with FITC-labeled SWCNTs-MG at a concentration of $30 \mathrm{mg} / \mathrm{L}$ for $6 \mathrm{~h}$. After $6 \mathrm{~h}$, the fish were transferred to clean water for breeding. tissues (gills, kidneys, spleen, liver, anterior intestine, middle intestine, and posterior intestine) were isolated from the vaccinated carps. Living body imaging system AniView 100 (BLT, China) was used to observe vaccinated carps and tissues at 5 different time points $(0,0.1,6,12$, and $24 \mathrm{~h})$ after the immersion immunization.

\section{Analysis on the activation and antigen presentation of APCs in vivo}

Carps were randomly divided into 7 groups (30 fish per group) and then immersed with PBS, SWCNTs, Mannose, G, MG, SWCNTs-G, and SWCNTs-MG at a concentration of $30 \mathrm{mg} / \mathrm{L}$ for $6 \mathrm{~h}$, respectively. After the bath administration, these fish were transferred to clean water for breeding. At 7 day after the immersion, head kidney tissues were isolated from vaccinated carps in different groups ( $n=9$, per group), then those tissues were homogenized, centrifugated and stored at $-80{ }^{\circ} \mathrm{C}$. The activation and antigen presentation of APCs were analyzed by using fish CD4, MHC-II, and CD80/86 ELISA kits (Renjiebio, China), respectively.

\section{Immune response analysis}

ELISA was used to analyze the antibody response and enzyme activity in vaccinated fish. The titers of the antibodies were measured by ELISA (Enzyme-linked immunosorbent assay) as described elsewhere [32]. For analyses of the presence of specific, neutralizing antibodies, vaccinated and control fish (3 fish of 3 independent experiments) were sampled weekly until 6 weeks for antibody determination. Serum samples preparation and determination were according to previous method. Briefly, the blood collected from the caudal vein of common carp was placed overnight at $4{ }^{\circ} \mathrm{C}$ and then centrifugated at $5000 \mathrm{~g}$ for $15 \mathrm{~min}$. The supernatant was collected and stored at $-20{ }^{\circ} \mathrm{C}$ until use. Purified recombinant $\mathrm{M}$ protein was used as antigen. Anti-Common carp (Cyprinus carpio carpio)/Koi carp (Cyprinus carpio koi) IgM monoclonal antibody labeled with horseradish peroxidase (Aquatic Diagostics Ltd., England) was diluted with PBS containing 3\% skimmed milk at the ratio of 1:1000 before use, followed by color development using tetramethylbenzidine, TMB (Tiangen Biotech, Beijing, China) was used as colorimetric substrate. The plate was read at $450 \mathrm{~nm}$ by using a precision microplate reader (Molecular Devices Corp., Palo Alto, CA).

For RNA isolation and cDNA synthesis cDNA synthesis, total RNAs were obtained from the kidney tissues in each group (3 fish per group) at 1, 3, 7, 14 and 21 days after vaccination with TRIzol reagent. HiScript Q Select RT SuperMix for aPCR (+gDNA wiper) (Vazyme, China) was performed to reverse transcribed the purified RNA into cDNA.

Quantitative real-time PCR (qRT-PCR) was performed with CFX96 Real-Time PCR Detection System (Bio-Rad, USA) using AceQ ${ }^{\circledR}$ qPCR SYBR ${ }^{\circledR}$ Green Master Mix (Vazyme, China) with the following procedure: $95{ }^{\circ} \mathrm{C}$ for 5 min and 40 cycles at $95^{\circ} \mathrm{C}$ denaturation for $15 \mathrm{~s}$, followed by $60{ }^{\circ} \mathrm{C}$ annealing for $60 \mathrm{~s}$. The extracted DNA were used as template for RT-PCR amplification with specific primers $\mathrm{SM}-\mathrm{F} / \mathrm{R}$. The $\beta$-actin was used as an internal control (Additional file 1: Table S1). All qRT-PCR reactions were performed for three biological replicates and repeated with two independent samples. Relative mRNA expression was calculated using $2^{-\triangle \triangle \mathrm{Ct}}$ method with the formula, $\mathrm{F}=2^{-}$ $\Delta \Delta \mathrm{Ct}, \Delta \Delta \mathrm{Ct}=(\mathrm{Ct}$, target gene $-\mathrm{Ct}$, reference gene $)-(\mathrm{Ct}$, target gene $-\mathrm{Ct}$, reference gene) control.

\section{Statistical analysis}

All data were analyzed using SPSS Software 21 (IBM). Differences in cell and tissues uptake capability were analyzed with Student's $t$ test $\left({ }^{*} P<0.05,{ }^{* *} P<0.01\right)$; Differences in APCs activation, antibody production and enzyme activities were analyzed by Duncan's test, values with different letters are significant $(P<0.05)$; The relative percentage survival was analyzed with Log-rank (Mantel-Cox) Test $\left({ }^{*} P<0.05,{ }^{* *} P<0.01\right)$.

\section{Supplementary information}

Supplementary information accompanies this paper at https://doi. org/10.1186/s12951-020-0584-X.

Additional file 1: Table S1. Primers used for the analysis of mRNA expression displayed; Figure S1. Synthetic route of mannose showed. Figure S2. ${ }^{1} \mathrm{HNMR}$ and ${ }^{13} \mathrm{C}$ NMR spectra of modified mannose showed.

\section{Authors' contributions}

CZ performed the experimental work. CZ contributed to the analysis and representation of data. The manuscript was written by $C Z$. All author revised the manuscript. BZ and GXW designed the study. All authors read and approved the final manuscript.

\section{Funding}

This work was supported by National Natural Science Foundation of China (Program No. 31602204), the Fundamental Research Funds for the Central Universities (2452017078) and the Special Funds for Talents in Northwest A \& F University to B. Zhu (Program No. Z111021510). 


\section{Availability of data and materials}

All data generated or analyzed during this study are included in this published article.

\section{Ethics approval and consent to participate}

No applicable.

\section{Competing interests}

The authors declare that they have no competing interests.

\section{Author details}

${ }^{1}$ College of Animal Science and Technology, Northwest A\&F University, Yangling 712100, China. ${ }^{2}$ Northwest A\&F University, Xinong Road 22nd, Yangling, Shaanxi 712100, China.

Received: 20 November 2019 Accepted: 22 January 2020 Published online: 30 January 2020

\section{References}

1. Debat HJ, Bejerman N. Novel bird's-foot trefoil RNA viruses provide insights into a clade of legume-associated enamoviruses and rhabdoviruses. Arch Virol. 2019;164(5):1-8.

2. Bedendo G, Panzarin V, Fortin A, Zamperin G, Pretto T, Buratin A, Quartesan R, Sabbion M, Salogni C, Pascoli F, Toffan A. Detection and characterization of a rhabdovirus causing mortality in black bullhead catfish, Ameiurus melas. J Fish Dis. 2018:41(7):1063-75.

3. Xu T, Chu Q, Cui J, Bi D. Inducible microRNA-3570 feedback inhibits the RIG-I-dependent innate immune response to rhabdovirus in teleost fish by targeting MAVS/IPS-1. J Virol. 2017;92(2):e01594.

4. Lee C, Hwang HS, Lee S, Kim B, Kim JO, Oh KT, Lee ES, Choi HG, Youn YS. Rabies virus-inspired silica-coated gold nanorods as a photothermal therapeutic platform for treating brain tumors. Adv Mater. 2017;29(13):1605563.

5. Ciabatti E, González-Rueda A, Mariotti L, Morgese F, Tripodi M. Life-long genetic and functional access to neural circuits using self-inactivating rabies virus. Cell. 2017;170(2):382-92.

6. Skinner LA, Lapatra SE, Adams A, Thompsonc KD, Balfryd SK, McKinleyad RS, Schultee PM. Concurrent injection of a rhabdovirus-specific DNA vaccine with a polyvalent, oil-adjuvanted vaccine delays the specific antiviral immune response in Atlantic salmon, Salmo salar L. Fish. Shellfish Immun. 2010:28(4):579-86.

7. Black JG, Lawson KF. The safety and efficacy of immunizing foxes (Vulpes vulpes) using bait containing attenuated rabies virus vaccine. Can J Comp Med. 1980:44:169176.

8. Rappuoli R, Black S, Lambert PH. Vaccine discovery and translation of new vaccine technology. Lancet. 2011;378(9788):360-8.

9. Takano T, Iwahori A, Hirono I, Aoki T. Development of a DNA vaccine against Hirame rhabdovirus and analysis of the expression of immuneeelated genes after vaccination. Fish Shellfish Immun. 2004;17(4):367-74.

10. Kurup D, Wirblich C, Feldmann H, Marzi A, Schnell MJ. Rhabdovirus-based vaccine platforms against henipaviruses. J Virol. 2015;89(1):144-54.

11. Rajput MK, Kesharwani SS, Kumar S, Muley P, Narisetty S, Tummala S. Dendritic cell-targeted nanovaccine delivery system prepared with an immune-active polymer. ACS Appl Mater Inter. 2018;10(33):27589-602.

12. Hu CMJ, Zhang L, Aryal S, Cheung C, Fang RH, Zhang L. Erythrocyte membrane-camouflaged polymeric nano-particles as a biomimetic delivery platform. Proc Natl Acad Sci USA. 2011;108:10980-5.

13. Embregts CWE, Rigaudeau D, Veselý T, Pokorová D, Lorenzen N, Petit J, Houel A, Dauber M, Schutze H, Boudinot P, Wiegertjes G, Florlenza M. Intramuscular DNA vaccination of juvenile carp against spring viremia of carp virus induces full protection and establishes a virus-specific B and T cell response. Front Immunol. 2017;8:1340.

14. Faria PCBD, Santos LID, Coelho JP, Ribeiro HB, Pimenta MA, Ladeira LO, Gomes DA, Furtado CA, Gazzinelli RT. Oxidized multiwalled carbon nanotubes as antigen delivery system to promote superior $\mathrm{CD}^{+} \mathrm{T}$ cell response and protection against cancer. Nano Lett. 2014;14(9):5458-70.

15. Smart SK, Cassady AI, Lu GQ, Martin DJ. The biocompatibility of carbon nanotubes. Carbon. 2006:44(6):1034-47.
16. Zhu B, Liu GL, Gong YX, Lin F, Song LS, Wang GX. Single-walled carbon nanotubes as candidate recombinant subunit vaccine carrier for immunization of grass carp against grass carp reovirus. Fish Shellfish Immun. 2014;41(2):279-93.

17. Guo Q, You H, Yang X, Lin B, Zhu Z, Lu Z, Li X, Zhao Y, Mao L, Shen S, Cheng H, Zhang J, Deng L, Fan J, Xi Z, Li R, Li CM. Functional single-walled carbon nanotubes 'CAR' for targeting dopamine delivery into the brain of parkinsonian mice. Nanoscale. 2017;9(30):10832-45.

18. Kafa H, Wang TW, Rubio N, Venner K, Anderson G, Pach E, Ballesteros B, Preston LE, Abbott NJ, Al-Jamal KT. The interaction of carbon nanotubes with an in vitro blood-brain barrier model and mouse brain in vivo. Biomaterials. 2015:53:437-52

19. Ecker BL, Mcmillan MT, Datta J, Lee MK, Karakousis GC, Vollmer CMJ, Drebin JA, Fraker DL, Roses RE. Adjuvant chemotherapy versus chemoradiotherapy in the management of patients with surgically resected duodenal adenocarcinoma: a propensity score-matched analysis of a nationwide clinical oncology database. Cancer. 2017;123(6):967-76.

20. Yang R, Xu J, Xu L, Sun XQ, Chen Q, Zhao YH, Peng R, Liu Z. Cancer cell membrane-coated adjuvant nanoparticles with mannose modification for effective anticancer vaccination. ACS Nano. 2018;12(6):5151.

21. Le Mercler L, Poujol D, Sanlaville A, Sisirak V, Gobert M, Durand L, Dubois B, Treilleux L, Marvel J, Vlach J, Blay JY, Bendriss-Vermare N, Caux C, Puisieux I, Goutagny N. Tumor promotion by intratumoral plasmacytoid dendritic cells is reversed by TLR7 ligand treatment. Cancer Res. 2013;73(15):4629-40.

22. Ashraf U, Lu Y, Lin L, Yuan J, Wang M, Liu X. Spring viraemia of carp virus: recent advances. J Gen Virol. 2016:97(5):1037-51.

23. Dikkeboom AL, Radi C, Toohey-Kurth K, Marcquenski S, Engel M, Goodwin AE, Stone AM, Longshaw C. First report of spring viremia of carp virus (SVCV) in wild common carp in north America. J Aquat Anim Health. 2004;16(4):169-78.

24. Zhang C, Li LH, Wang J, Zhao Z, Li J, Tu X, Huang AG, Wang GX, Zhu $B$. Enhanced protective immunity against spring viremia of carp virus infection can be induced by recombinant subunit vaccine conjugated to single-walled carbon nanotubes. Vaccine. 2018;36(42):6334-44.

25. Zhang C, Zhao Z, Zha JW, Wang GX, Zhu B. Single-walled carbon nanotubes as delivery vehicles enhance the immunoprotective effect of a DNA vaccine against spring viremia of carp virus in common carp. Fish Shellfish Immunol. 2017;71:191-201.

26. Warheit DB, Laurence BR, Reed KL, Roach DH, Reynolds GA, Webb TR. Comparative pulmonary toxicity assessment of single-wall carbon nanotubes in rats. Toxicol Sci. 2004:77(1):117-25.

27. Zhu B, Liu GL, Ling F, Song LS, Wang GX. Development toxicity of functionalized single-walled carbon nanotubes on rare minnow embryos and larvae. Nanotoxicology. 2014;9(5):579-90.

28. Zhu S, Luo F, Li J, Zhu B, Wang GX. Biocompatibility assessment of single-walled carbon nanotubes using saccharomyces cerevisiae as a model organism. J Nanobiotechnol. 2018;16(1):44.

29. Norihiro K, Masato N, Kohei M, Kazuhiro Y, Makoto E, Junko N. Pulmonary and systemic responses of highly pure and well-dispersed single-wall carbon nanotubes after intratracheal instillation in rats. Inhal Toxicol. 2011;23(13):814-28.

30. Dumortier H, Lacotte S, Pastorin G, Marega R, Wu W, Bonifazi D, Briand JP, Prato M, Muller S, Bianco A. Functionalized carbon nanotubes are non-cytotoxic and preserve the functionality of primary immune cells. Nano Lett. 2006;6(7):1522-8.

31. Montesfonseca SL, Orrantiaborunda E, Aguilarelguezabal A, González HC, Talamásrohana P, Sánchezramírez B. Cytotoxicity of functionalized carbon nanotubes in J774A macrophages. New Biotechnol. 2012;8(6):853-9.

32. Dineshkumar B, Krishnakumar K, Bhatt AR, Paul D, Cherian J, John A, Suresh S. Single-walled and multi-walled carbon nanotubes based drug delivery system: cancer therapy: a review. Indian J Cancer. 2015;52:262.

33. Rastogi V, Yadav P, Bhattacharya SS, Mishra AK, Verma N, Verma A, Pandit JK. Carbon naonotubes: an emerging drug carrier for targeting cancer cells. J Drug Deliv. 2014;2014(670815):670815.

34. Shi X, Balaji S, Pham QP, Spicer PP, Hudson JL, Wilson LJ, Tour JM, Raphael RM, Mikos AG. In vitro cytotoxicity of single-walled carbon nanotube/ biodegradable polymer nanocomposites. J Biomed Mater Res A. 2010;86(3):813-23. 
35. Vono M, Lin A, Norrby-Teglund A, Koup RA, Liang F, Lore K. Neutrophils acquire the capacity for antigen presentation to memory $\mathrm{CD}^{+}{ }^{\mathrm{T}}$ cells in vitro and ex Vivo. Blood. 2017;129(14):1991-2001.

36. Yang Q, Pan YL, Wang KY, Wang J, He Y, Wang EL, Huang XL. OmpN, outer membrane proteins of Edwardsiella ictaluri are potential vaccine candidates for channel catfish (Ictalurus punctatus). Mol Immunol. 2016;78:1-8.

37. Petousisharris H, Paynter J, Morgan J, Saxton P, McArdle B, GoodyearSmith F, Black S. Effectiveness of a group B outer membrane vesicle meningococcal vaccine against gonorrhoea in New Zealand: a retrospective case-control study. Lancet. 2017;390(10102):1603-10.

38. Tunuguntla RH, Henley RY, Yao YC, Pham TA, Wanunu M, Noy A. Enhanced water permeability and tunable ion selectivity in subnanometer carbon nanotube porins. Science. 2017;357(6383):792-6.

39. Duffield JS. Macrophages and immunologic inflammation of the kidney Semin Nephrol. 2010;30(3):234-54

40. Chen $Z Y$, Lei $X Y$, Zhang QY. The antiviral defense mechanisms in mandarin fish induced by DNA vaccination against a rhabdovirus. Vet Microbiol. 2012;157(3-4):264-75.

41. Hoare R, Ngo TPH, Bartie KL, Adams A. Efficacy of a polyvalent immersion vaccine against Flavobacterium psychrophilum and evaluation of immune response to vaccination in rainbow trout fry (Onchorynchus mykiss $L$ ). Vet Res. 2018:48(1):43.

42. Navot N, Kimmel E, Avtalion RR. Enhancement of antigen uptake and antibody production in goldfish (Carassius auratus) following bath immunization and ultrasound treatment. Vaccine. 2004;22(20):2660-6.

43. Valladão GMR, Gallani SUG, Pala G, Jesus RB, Kotzent S, Costa JC, Silva TFA, Pilarski F. Practical diets with essential oils of plants activate the complement system and alter the intestinal morphology of nile tilapia. Aquat Res. 2017:48(11):5640-9.

44. Yin F, Gong H, Ke Q, Li A. Stress, antioxidant defence and mucosal immune responses of the large yellow croaker Pseudosciaena Crocea challenged with cryptocaryon irritans. Fish Shellfish Immunol. 2015;47:344-51.

45. Zhao YC, Zhang WB, Xu W, Mai KS, Zhang YJ, Liufu ZG. Effects of potential probiotic bacillus subtilis T13 on growth, immunity and disease resistance against vibrio splendidus infection in juvenile sea cucumber apostichopus japonicus. Fish Shellfish Immunol. 2012;32(5):750-5.

46. Medzhitov R Jr. Innate immune recognition and control of adaptive immune responses. Semin Immunol. 2016;10(5):351-3.
47. Tian JY, Sun BJ, Luo YP, Zhang YG, Nie P. Distribution of $\lg M$, IgD and $\lg Z$ in mandarin fish, Siniperca Chuatsi lymphoid tissues and their transcriptional changes after Flavobacterium Columnare stimulation. Aquaculture. 2009;288(1-2):14-21.

48. Chaui-Berlinck JG, Barbuto JAM, Monteiro LHA. Conditions for pathogen elimination by immune systems. Theor Biosci. 2004;123(2):195-208.

49. Paul WE, Seder RA. Lymphocyte responses and cytokines. Cell. 1994;76:241-51.

50. Shibata $Y$, Foster LA, Kurimoto M, Okamura H, Nakamura RM, Kawajiri K, Metzqer WJ. Immunoregulatory roles of IL-10 in innate immunity: IL-10 inhibits macrophage production of IFN-gamma-inducing factors but enhances NK cell production of IFN-gamma. J Immunol. 1998;161(8):4283-8.

51. Cerami A. TNF and ePO: major players in the innate immune response: their discovery. Ann Rheum Dis. 2012;71(Suppl 2):i55-9.

52. Grasso V, Padilla D, Bravo J, Román L, Rosario I, Acosta B, Acosta F. Immunization of sea bream (Sparus Aurata) juveniles against photobacterium damselae subsp piscicida by short bath: effect on some pro-inflammatory molecules and the $\mathrm{m} \times$ gene expression. Fish Shellfish Immun. 2015:46(2):292-6.

53. Hashimoto S, Billings P, Harris JP, Firestein GS, Keithley EM. Innate immunity contributes to cochlear adaptive immune responses. Audiol NeuroOtol. 2005;10(1):35-43.

54. Ding C, Fan E, Wang S, Guo L, Li J, Liu Q. A potential aquaculture vaccine vector: evaluation of a double-gene attenuated listeria monocytogenes, in zebrafish (Danio Rerio). Aquaculture. 2017;479(1):311-20.

55. Adamek M, Rakus KL, Chyb J, Brogden G, Huebner A, Irnazarow I, Steinhagen D. Interferon type I responses to virus infectious in carp cells: in vitro studies on Cyprinid herpesvirus 3 and Rhabdovirus Carpio infections. Fish Shellfish Immun. 2012;33:482-93.

\section{Publisher's Note}

Springer Nature remains neutral with regard to jurisdictional claims in published maps and institutional affiliations.
Ready to submit your research? Choose BMC and benefit from:

- fast, convenient online submission

- thorough peer review by experienced researchers in your field

- rapid publication on acceptance

- support for research data, including large and complex data types

- gold Open Access which fosters wider collaboration and increased citations

- maximum visibility for your research: over $100 \mathrm{M}$ website views per year

At BMC, research is always in progress.

Learn more biomedcentral.com/submissions 